\title{
Green Machining of a Thermoplastic Ceramic-Ethylene Ethyl Acrylate/ Isobutyl Methacrylate Compound
}

\author{
Young-Hag Koh* and John W. Halloran ${ }^{\star}$ \\ Materials Science and Engineering Department, University of Michigan, Ann Arbor, Michigan, 48109-2136
}

\begin{abstract}
The machinability of a thermoplastic compound that consisted of 52 vol\% ceramic particles and 48 vol\% thermoplastic binders was investigated. To investigate the machining mechanisms, various blends of a ductile polymer (ethylene ethyl acrylate (EEA)) and a brittle polymer (isobutyl methacrylate (IBMA)) were used as thermoplastic binders. The fraction of IBMA to EEA in the blend was increased from 0 to 50 vol\%. As the IBMA content was increased, the thermoplastic compound exhibited a stiffer stress versus strain response under compression because of the brittle nature of the IBMA polymer. The machinability of the thermoplastic compound was remarkably improved with increased IBMA content because of the mitigation of the extensive deformation of the thermoplastic compound.
\end{abstract}

\section{Introduction}

$\mathrm{C}$ OMPUTER-NUMERIC-CONTROLLED (CNC) machining has been prevalently used as a rapid-prototyping method for making complicated objects because of its cost effectiveness. ${ }^{1}$ The most attractive way to machine ceramic parts is to machine the ceramic parts before densification and to use partially sintered bodies ${ }^{2}$ and powder compacts. ${ }^{3-5}$ The machinability of a ceramic green body is dependent on the characteristics of the green body and the machining conditions. The green body must possess sufficient mechanical interlocking between the ceramic particles through the use of binders to avoid chipping by machining. More recently, various types of ceramic parts that contain binders have been studied for green machining. ${ }^{6-9}$

Generally, material in a ceramic green body is removed in a brittle manner by machining. As a consequence, a slow machining speed should be selected; otherwise, the part tends to generate defects and poor edge retention. ${ }^{10,11}$ Therefore, it is desirable to mitigate the brittle nature, while maintaining sufficient strength for machining. One of the possible ways is to use a thermoplastic compound comprised of ceramic particles and thermoplastic binders, which have been extensively used in coextrusion processes. ${ }^{12,13}$ Ethylene ethyl acrylate (EEA) thermoplastic polymer has been widely used because of high flexibility, good melt strength, and excellent processability due to its low glass-transition temperature $\left(T_{\mathrm{g}}=-80^{\circ} \mathrm{C}\right)$. The ductile nature with extensive elongation capacity of EEA can be modified by incorporating a brittle thermoplastic polymer, such as isobutyl methacrylate (IBMA), which has a lower $T_{\mathrm{g}}\left(65^{\circ} \mathrm{C}\right)$.

R. Riedel-contributing editor
Therefore, in this work, we investigated the machinability of a thermoplastic compound. We used novel CNC green machining, named "thermoplastic green machining" (TGM), to make complex, engineered ceramics. For a fundamental understanding of this process, thermoplastic compounds comprised of $52 \mathrm{vol} \%$ of ceramic particles and 48 vol\% of various EEA/IBMA thermoplastic binders were machined using a mini-CNC machine. The machinability was characterized in terms of surface roughness, using scanning electron microscopy, which was related to the characteristics of the thermoplastic compound and machining mechanisms. An example for the actual application was fabricated and examined. Machinability in the green stage and shape tolerance after sintering also were studied.

\section{Experimental Procedure}

A commercially available ceramic powder (ULF101, Ferro Corp., Cleveland, $\mathrm{OH})^{\dagger}$ with a mean particle size of $0.8 \mu \mathrm{m}$ and specific surface area of $4.8 \mathrm{~m}^{2} / \mathrm{g}$ was used. The powder was ball-milled using alumina balls for $24 \mathrm{~h}$, and then it was dried at $85^{\circ} \mathrm{C}$ for $>24 \mathrm{~h}$. The dried powder was blended with a thermoplastic binder that consisted of EEA (EEA 6182, Union Carbide, Danbury, CT) and IBMA (Paraloid B67, Rohm and Haas, Philadelphia, PA), using a heated high-shear mixer (Model PlastiCorder PL 2100 electronic torque rheometer, C. W. Brabender, South Hackensack, NJ) at $130^{\circ} \mathrm{C}$. Processing aids, such as poly(ethylene glycol) and heavy mineral oil, also were added to ensure a consistent apparent viscosity value during blending.

Various thermoplastic EEA/IBMA binders were used to investigate the machining mechanisms of thermoplastic compounds because of the ductile and brittle natures of EEA and IBMA polymers, respectively. The amount of IBMA to EEA polymer in the thermoplastic binder was increased from 0 to 50 vol\%. Further incorporation of IBMA ( $>50 \mathrm{vol} \%)$ generated an inhomogeneous mixture. Regardless of the amount of IBMA in the thermoplastic binder, the thermoplastic compounds exhibited similar viscosities $(\sim 3000 \mathrm{~Pa} \cdot \mathrm{s})$ at $130^{\circ} \mathrm{C}$. The mixing behavior of the EEA/IBMA blend was characterized using differential scanning calorimetry (DSC; Model DSC-7, Perkin-Elmer, Norwalk, CT). Three samples (i.e., pure EEA, pure IBMA, and EEA/IBMA blend) were heated at $5^{\circ} \mathrm{C} / \mathrm{min}$ up to $130^{\circ} \mathrm{C}$ and furnace-cooled, and the heat flux was monitored.

Once it was compounded, the thermoplastic compound was warm-pressed using a $38 \mathrm{~mm}^{2}$ mold at $140^{\circ} \mathrm{C}$ for $1 \mathrm{~h}$ with an applied load of $10 \mathrm{MPa}$. The green body was sliced to a dimension of $38 \mathrm{~mm} \times 38 \mathrm{~mm} \times 3 \mathrm{~mm}$. The stress versus strain response under compression of the green body was performed using a screw-driven load frame (Model 4483, Instron Corp., Canton, MA) equipped with a $5 \mathrm{kN}$ load cell. The green bodies were milled using a mini-CNC machine (Model a, Roland DGA Corp., Irvine,

Manuscript No. 10647. Received November 2, 2003; approved March 26, 2004. Supported by Defense Advanced Research Project under Contract No. N0017301-1-G910.

${ }^{\star}$ Member, American Ceramic Society.

${ }^{\dagger}$ We used the dielectric glass-ceramic, mainly composed of Bi-Ba-Nd-titanate, to fabricate the textured dielectric substrate for wireless communication. 


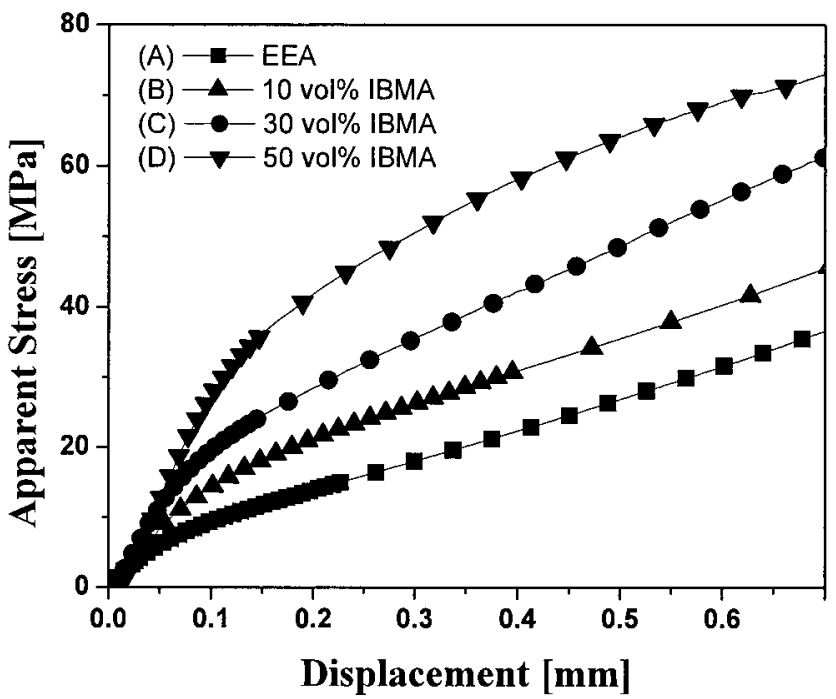

Fig. 1. Apparent stress responses versus displacement under compression of thermoplastic compound comprised of $52 \mathrm{vol} \%$ ceramic particles and various 48 vol\% thermoplastic binders: (A) EEA, (B) 10 vol\% IBMA, (c) 30 vol\% IBMA, and (D) 50 vol\% IBMA.

CA). The milling was conducted using a carbide end mill with a diameter of $1.57 \mathrm{~mm}$ at $6500 \mathrm{rpm}$.

After the thermoplastic compounds containing various binders were milled, their machinability was characterized in terms of surface roughness using scanning electron microscopy (SEM). The improvement in machinability by incorporating IBMA into EEA binder was related to the characteristics of the thermoplastic compound and the machining mechanisms. An actual object was fabricated and characterized based on this process, in terms of machinability (such as surface roughness and edge retention) and sinterability.

\section{Results and Discussion}

The mixing behavior of the EEA/IBMA blend was characterized using DSC analyses. After it was heated, the mixed $50 \mathrm{vol} \%$ EEA/50 vol \% IBMA blend exhibited an endothermic peak at $105^{\circ} \mathrm{C}$, which corresponded to the melting of the EEA. A trace of a glass-transition peak of IBMA at $70^{\circ} \mathrm{C}$ was observed; however, a glass transition of EEA was not detected because of a low $T_{\mathrm{g}}$ $\left(-80^{\circ} \mathrm{C}\right.$, according to manufacturer data). However, the crystallization peak of EEA was observed at $82^{\circ} \mathrm{C}$ on cooling. These results implied that the EEA/IBMA blend was immiscible, as is often the case of polymer blends. ${ }^{14}$ Therefore, brittle IBMA polymers were expected to be dispersed in the ductile EEA polymer, which, consequently, improved the mechanical properties of the blend.

The stress versus strain responses under compression of the thermoplastic compounds that contained various EEA/IBMA binders are shown in Figs. 1 (A)-(D). Contrary to the brittle fracture of conventional ceramic compacts, all current samples exhibited extensive deformations because of the presence of ductile EEA polymer with extensive elongation capacity. However, the sample showed the stiffer stress versus strain response with increased IBMA polymer content because of its brittle nature with less elongation capacity. When no IBMA was incorporated (Fig. 1(A)), the sample exhibited $0.55 \mathrm{~mm}$ displacement under $30 \mathrm{MPa}$. However, the sample containing 50 vol\% EEA/50 vol\% IBMA binder (Fig. 1(D)) exhibited remarkably decreased displacement

(A)
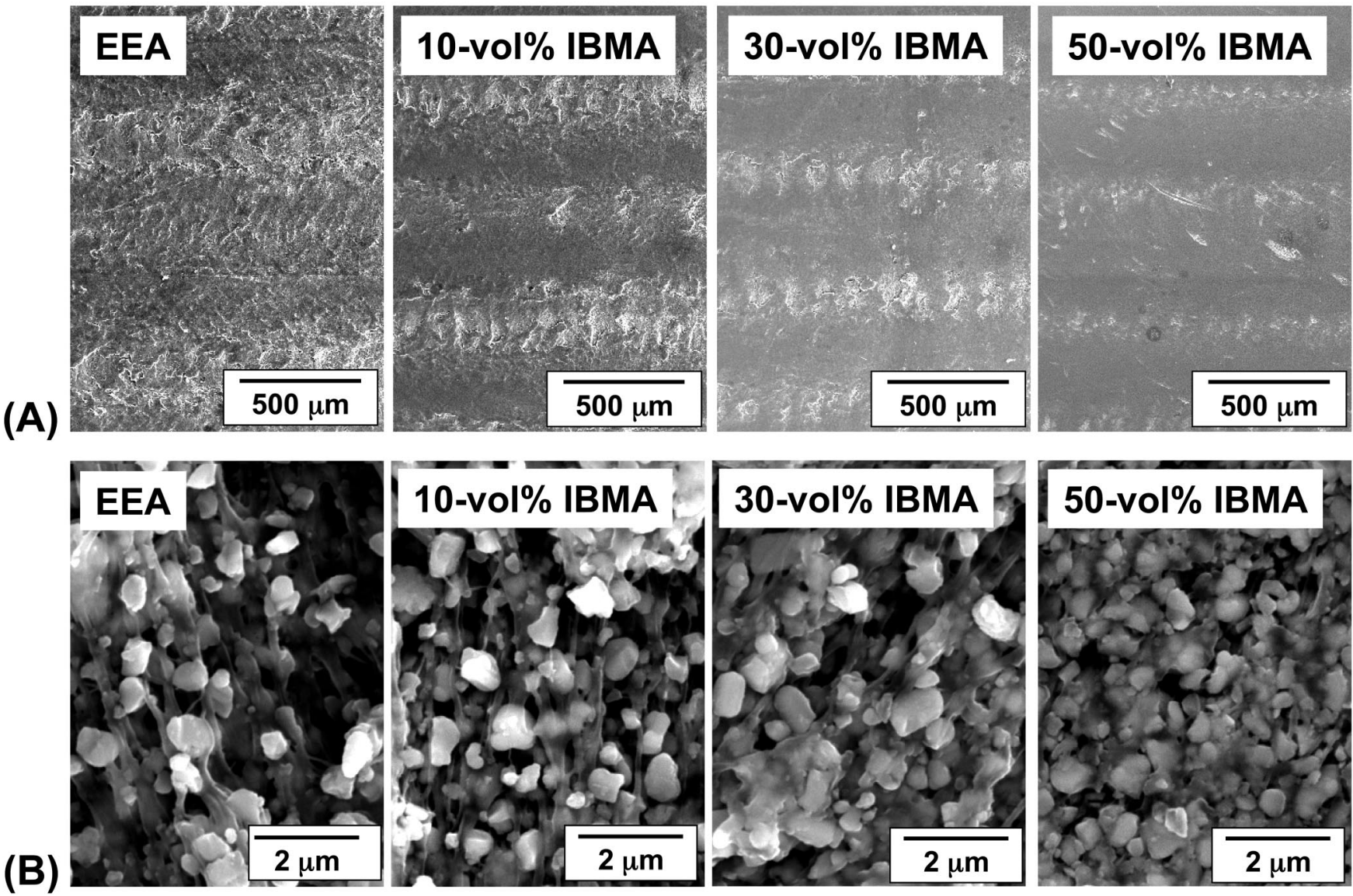

Fig. 2. (A) As-machined surfaces at low magnification that show the degree of surface roughness during machining and (B) high-magnification micrograph at the scale of grain size that shows the decreased ductile rupture of the EEA by addition of IBMA. 

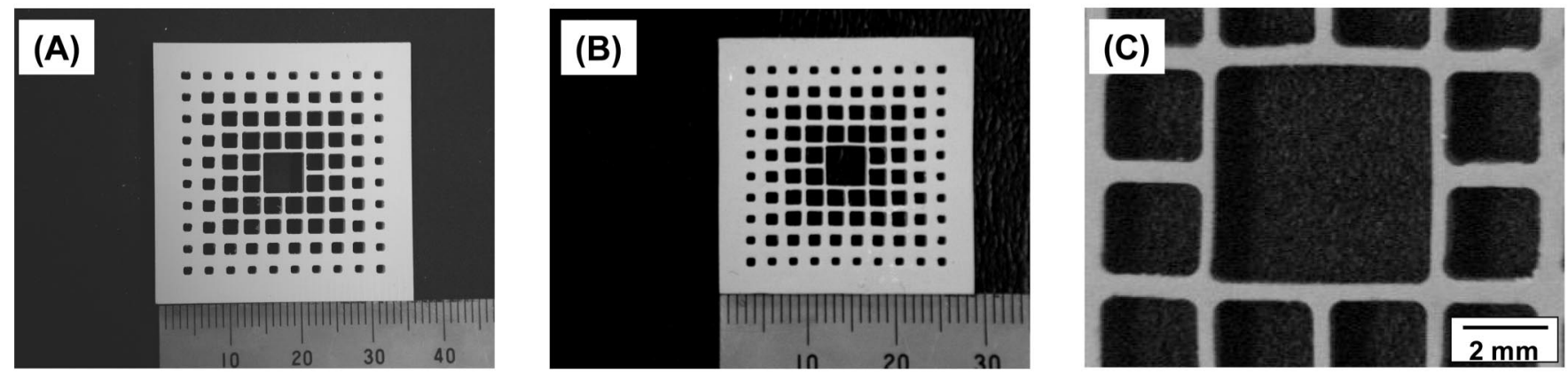

Fig. 3. Optical micrographs of (A) as-machined green body, (B) sintered body after $19 \%$ linear shrinkage, and (C) detail of inner web that shows $230 \mu \mathrm{m}$ wall thickness.

$(0.2 \mathrm{~mm})$ under the same stress, which implied less deformation at the machining zone.

The thermoplastic compounds with various EEA/IBMA blends were machined, and they were observed in terms of surface roughness, as shown in Fig. 2(A). The surface roughness was strongly dependent on the composition of thermoplastic binder. When no IBMA was incorporated into the EEA polymer, severe rough surfaces were observed. More severe surface damage was formed along the machining direction because of the geometry of the carbide end mill. However, as the amount of IBMA into EEA in the blend increased, the surface roughness was remarkably decreased. The sample that contained 50 vol\% EEA/50 vol\% IBMA binder (denoted as 50 vol\% IBMA) revealed a good surface finish.

The surface damages of the samples at the scale of grain size are shown in Fig. 2(B). Severe ductile rupture, with tearing and extensive pullouts of ceramic particles on the surface region, was observed with no incorporation of IBMA (pure EEA). However, as the IBMA content was increased, the ductile rupture on the machined surface was remarkably decreased. The sample containing 50 vol\% EEA/50 vol\% IBMA binder (50 vol\% IBMA) exhibited negligible tearing and pullouts of ceramic particles. These results were attributed to the mitigation of the extensive ductile fracture of the thermoplastic compound by incorporating brittle IBMA polymer into ductile EEA polymer.

During the machining of the thermoplastic polymer, the material can be removed in the ductile or brittle manner, depending on the characteristics of the polymer related to the $T_{\mathrm{g}}{ }^{15}$ If the local temperature is $<T_{\mathrm{g}}$ of the polymer, the material tends to be removed in a brittle manner, as is the case of the IBMA polymer $\left(T_{\mathrm{g}}=65^{\circ} \mathrm{C}\right)$. Otherwise, the material tends to be removed in a ductile manner, with extensive deformation or melting, as is the case of EEA $\left(T_{\mathrm{g}}=-80^{\circ} \mathrm{C}\right)$. Therefore, the improved machinability from incorporating IBMA into EEA binder is attributed to the modification of the material removal manner. In other words, for good surface finish, the material should be removed in a nonbrittle manner, while the tearing and pullouts of ceramic particles due to extensive deformation or melting should be diminished. Also, the heat generated at the machining zone might affect the surface finish of the thermoplastic compound.

Based on these investigations, an object possessing various voids was fabricated. A predetermined amount of the material was accurately removed in the specific position according to the original design using a mini-CNC machine, consequently leaving various voids in the green body, as shown in Fig. 3(A). After the binder was appropriately removed at a slow heating rate up to $500^{\circ} \mathrm{C}$ in nitrogen, the sample was sintered at $980^{\circ} \mathrm{C}$ for $5 \mathrm{~h}$ in air. The sintered sample exhibited good shape tolerance without generating defects, such as cracking and distortion (Fig. 3(B)). The fracture surface revealed negligible porosity, which implied almost complete densification. The thin inner web showed good shape retention with a wall thickness of $230 \mu \mathrm{m}$, as shown in Fig. 3(C). An even finer scale can be achieved using this novel process because of the material removal in a nonbrittle manner during machining.

\section{Summary and Conclusions}

Novel thermoplastic green machining was investigated as a rapid-prototyping $\mathrm{CNC}$ green machining process for ceramic parts. A thermoplastic compound was prepared by blending 52 vol\% ceramic particles and 48 vol\% thermoplastic binder, which consisted of ductile EEA $\left(T_{\mathrm{g}}=-80^{\circ} \mathrm{C}\right)$ and brittle IBMA $\left(T_{\mathrm{g}}=\right.$ $70^{\circ} \mathrm{C}$ ) polymers. As the IBMA into EEA polymer content in the thermoplastic binder was increased from 0 to $50 \mathrm{vol} \%$, a stiffer stress versus stain response was observed because of the brittle nature of the IBMA polymer. The surface roughness, such as tearing and pullouts of ceramic particles, was remarkably decreased by incorporating IBMA into the EEA binder. Such improved machinability was attributed to the mitigation of the extensive deformation and melting of the thermoplastic binder, while maintaining material removal in a nonbrittle manner. A precisely machined sample could be obtained with a thin-wall thickness $(\sim 230 \mu \mathrm{m})$ using this novel process.

\section{References}

${ }^{1}$ R. Hassold, "CNC Machining as Rapid-Prototyping Technique," Mod. Mach Shop, 68 [5] 68-73 (1995).

${ }^{2}$ D. L. Halcomb and M. C. Rey, "Ceramic Cutting Tools for Machining Unsintered Compacts of Oxide Ceramics," Am. Ceram. Soc. Bull., 61, 1311-14 (1982).

${ }^{3}$ X. L. K. W. Wu and W. J. Mcanany, "Acrylic Binder for Green Machining," Am. Ceram. Soc. Bull., 74 [5] 61-64 (1995).

${ }^{4}$ J. H. Song and J. R. G. Evans, "On the Machinability of Ceramic Compacts," J. Eur. Ceram. Soc., 17 [14] 1665-73 (1997).

${ }^{5}$ D. B. R. Kumar, M. R. Reddy, V. N. Mulay, and N. Krishnamurti, "Acrylic Co-polymer Emulsion Binders for Green Machining of Ceramics,” Eur. Polym. J., 36 [7] 1503-10 (2000).

${ }^{6} \mathrm{~W}$. L. Scheller II and W. Wanumuhama, "Machining of Green $\mathrm{Si}_{3} \mathrm{~N}_{4}$ PolymerBonded Ceramic Materials," Mater. Manuf. Processes, 11 [5] 775-87 (1996).

${ }^{7}$ T. Besshi, T. Sato, and T. I. Tsutsui, "Machining of Alumina Green Bodies and Their Dewaxing," J. Mater. Processes Technol., 95 [1-3] 133-38 (1999).

${ }^{8}$ S. D. Nunn and G. H. Kirby, "Green Machining of Gelcast Ceramic Materials," Ceram. Eng. Sci. Proc., 17 [3] 209-13 (1996).

${ }^{9}$ M. D. Vlajic and V. D. Krstic, "Strength and Machining of Gelcast SiC Ceramics," J. Mater. Sci., 37 [14] 2943-47 (2002).

${ }^{10}$ M. Nishi and T. Sugita, "Strength Reliability Evaluation of Ceramics with Machining," J. Jpn. Soc. Powder Powder Metall., 41 [11] 1405-11 (1994).

${ }^{11}$ E. Sentoku, H. Tanaka, and H. Kawabata, "On the Machinability for AluminaMolding Pieces (1st Part)—Cutting Conditions and Roughness of Finished Surface," J. Jpn. Soc. Powder Powder Metall., 43 [4] 493-97 (1996).

${ }^{12}$ Y. H. Koh, H. W. Kim, H. E. Kim, and J. W. Halloran, "Fabrication and Compressive Strength of Macrochanneled Tetragonal-Zirconia Polycrystals with Calcium Phosphate Coating Layer," J. Mater. Res., 18 [9] 2009-12 (2003).

${ }^{13}$ Y. H. Koh, A. Knapp, J. W. Halloran, H. W. Kim, and H. E. Kim, "Co-firing of Textured Dielectric Ca-Mg-Silicate and Bi-Ba-Nd-Titanate Composite," J. Am. Ceram. Soc., in review.

${ }^{14}$ L. A. Utracki, Polymer Alloys and Blends: Thermodynamics and Rheology; pp. 29-30. Hanser, New York, 1989.

${ }^{15}$ K. Q. Xiao and L. C. Zhang, "The Role of Viscous Deformation in the Machining of Polymers," Int. J. Mech. Sci., 44 [11] 2317-36 (2002). 